Fumiyo Murakami • Tokio Shimomura • Kazuhiko Kotani Shiro Ikawa · Eiji Nanba $\cdot$ Kaori Adachi

\title{
Anxiety traits associated with a polymorphism in the serotonin transporter gene regulatory region in the Japanese
}

Received: July 16, 1998 / Accepted: August 25, 1998

\begin{abstract}
We determined polymorphism in the serotonin (5-HT) transporter gene-linked polymorphic region (5HTTLPR) in 501 healthy Japanese, individuals, using the polymerase chain reaction of Lesch et al., with minor modifications. The distribution of allele frequencies was determined and found to differ from that in Caucasians. We also investigated the relationship of polymorphism in 5HTTLPR to anxiety traits, by having 189 of the 501 subjects complete a self-rating questionnaire for anxiety and depression. Subjects with the short/short (s/s) genotype had significantly higher anxiety scores than those with the long/long $(1 / 1)$ or $1 / \mathrm{s}$ genotype. It is suggested that populations with the $\mathrm{s} / \mathrm{s}$ genotype of 5-HTTLPR have stronger anxiety-related personality traits than those with the 1 allele.
\end{abstract}

Key words Serotonin transporter gene-linked polymorphic region $(5$-HTTLPR) $\cdot$ Healthy Japanese $\cdot$ Frequency distribution $\cdot$ Anxiety traits $\cdot$ SRQ-AD

\section{Introduction}

Neurotransmission mediated by serotonin (5-HT) contributes to many physiological functions, such as motor activity, food intake, sleep, and emotional states (Chen et al. 1992; Hensler et al. 1994). By regulating 5-HT responses, the 5HT transporter (5-HTT) is central to both the fine-tuning of brain serotonergic neurotransmission, and to the peripheral actions of 5-HT (Chen et al. 1992; Hensler et al. 1994).

F. Murakami · T. Shimomura $(\varangle) \cdot$ S. Ikawa

Department of Clinical Laboratory Medicine, Tottori University,

Faculty of Medicine, Yonago 683-8504, Japan

Tel. +81-859-34-8331; Fax +81-859-34-8081

e-mail: toshimo@grape.med.tottori-u.ac.jp

K. Kotani

Department of Internal Medicine, Akasaki Public Clinic, Akasaki, Japan

E. Nanba $\cdot$ K. Adachi

Gene Research Center, Tottori University, Yonago, Japan
The human 5-HTT gene is mapped to human chromosome 17q12 (Lesch et al. 1994), and polymorphism in the transcriptional control region upstream of the 5-HTT coding sequence was reported by Helis et al. (1995). The polymorphism consists of long and short variants of the 5-HTT gene-linked polymorphic region (5-HTTLPR), which are located about $1 \mathrm{~kb}$ upstream of the $5-H T T$ gene transcription initiation site and are composed of 16 repeat elements. Recently, Lesch et al. (1996) reported that this polymorphism was related to anxiety-related traits in healthy Caucasian subjects.

In this study, we investigated the distribution of the genotypes and allele frequencies of the 5-HTTLPR in 501 healthy Japanese individuals, and compared the findings with the reported rates in Caucasians. In 189 of the 501 volunteers, we evaluated the role of the 5-HTTLPR in anxiety traits by having the subjects complete a self-rating questionnaire for anxiety and depression (SRQ-AD) derived from the Primary Care Anxiety and Depression Scale (ElRufaie et al. 1997).

\section{Subjects and methods}

Blood samples were drawn (after informed consent was obtained, according to the aim and the guideline of Tottori University's Ethics Committee for Experimentation on Humans) from 501 healthy unrelated volunteers (232 women and 269 men), aged 19-81 years (mean age, $47.9 \pm$ 10.4 years) living in the San-in area of Japan (Tottori and Shimane prefectures).

Genomic DNA was isolated from leukocytes, using a DNA extraction kit (DNA Quick DNA extraction kit; DaiNippon Pharmaceutical, Tokyo, Japan), and the extracted DNA was amplified by polymerase chain reaction (PCR), according to the method of Lesch et al. (1996), with minor modifications. Oligonucleotide primers flanking the 5HTTLPR and corresponding to the nucleotide positions -1416 to -1397 (LPRF, 5'-GGCGTTGCCGCTCTGAATGC) and -910 to -888 (LPRR 3, 5'-GAGGGACTG- 
ACGTGGACAACCAC) of the 5-HTT gene 5'-flanking regulatory region were used to generate 484- or 528-bp fragments. The amplification was carried out for 35 cycles $\left(94^{\circ} \mathrm{C}\right.$ for $30 \mathrm{~s}, 63^{\circ} \mathrm{C}$ for $30 \mathrm{~s}, 72^{\circ} \mathrm{C}$ for $\left.80 \mathrm{~s}\right)$ in a $25-\mu 1$ aliquot of reaction mixture with $75 \mathrm{ng}$ genomic DNA, $12.5 \mathrm{pmol}$ primers and 0.3 U King of DNA (KOD) polymerase (KOD Dash; Toyobo, Osaka, Japan) using a programmable thermal cycler (PC-960G Gradient thermal cycler; Corbett Research, Mortlake, NSW, Australia).

The reaction products were electrophoresed through $2.0 \%$ agarose gel and visualized by ultraviolet illumination in the presence of ethidium bromide. Hardy-Weinberg equilibrium (HWE) was examined, using the $\chi^{2}$ test.

One hundred and eighty-nine ( 72 women and 117 men) aged 19-81 years (mean age, $49.3 \pm 14.2$ years) of the 501 volunteers selected randomly were given the SRQ-AD (Tsutsui 1981). The SRQ-AD is a screening test for the detection of masked depression and consists of 18 items, including 6 control questions. We selected 5 anxiety items (questions number $7,9,13,14,18$ ) and 8 psychic depression items (questions number $1,3,5,7,11,15,16,17$ ) by reference to the method of El-Rufaie et al. (1997) and obtained total scores (TS), anxiety scores (AS), and depression scores (DS). Statistical analysis was performed using the $t$-test.

\section{Results and discussion}

The PCR products of the 484- and 528-bp fragments containing a 44-bp deletion or insertion region were amplified using the primers $5^{\prime}$-flanking regulatory region (LPRF and LPRR). We denoted the products of the 528-bp fragments as the long (l) allele and the products of the 484-bp fragments as the short (s) allele, according to the method of Lesch et al. (1996).

The frequency distribution of the $1 / 1,1 / \mathrm{s}$, and $\mathrm{s} / \mathrm{s} 5$ HTTLPR genotypes in the 501 healthy subjects was 0.031 $(n=16), 0.317(n=159)$, and $0.652(n=326)$, respectively, and was not significantly different in men and women. The allele frequencies for the (1) and (s) alleles were 0.191 and 0.809 . The observed genotype frequencies were similar to the HWE expected frequencies.

Lesch et al. (1996) reported that PCR-based genotype analysis in Caucasian subjects revealed allele frequencies of 0.57 for the (1) and 0.43 for the (s) allele, with the distribution of the $1 / 1,1 / \mathrm{s}$, and s/s 5-HTTLPR genotypes according to HWE being $0.32,0.49$, and 0.19 , respectively. The distribution of alleles in Caucasians was significantly different from that in our Japanese population $\left(\chi^{2}=30.65\right.$; degrees of freedom $[\mathrm{df}]=1 ; P<0.001)$. These findings suggest that there are different allele frequencies in various ethnic groups. The difference in allele frequency between Japanese and Caucasian populations, with the low frequency of the (1) allele in Japanese, may affect some personality traits in the Japanese population.

The human serotonin transporter gene is a strong candidate for involvement in the pathogenesis of mood disorder. Transporter-facilitated uptake of 5-HT has been implicated
Table 1 SRQ-AD scores in relation to 5-HTTLPR genotype in 189 healthy Japanese individuals

\begin{tabular}{lccl}
\hline & $\begin{array}{l}\text { Group L } \\
\text { (1/l and 1/s } \\
\text { genotypes) }\end{array}$ & $\begin{array}{l}\text { Group S } \\
\text { (s/s genotype) }\end{array}$ & $P$ value $^{\mathrm{a}}$ \\
\hline Number of subjects & 65 & 124 & \\
Age (years) & $49.3 \pm 13.4$ & $49.1 \pm 14.8$ & $\mathrm{NS}$ \\
SRQ-AD-TS & $4.8 \pm 3.6$ & $5.3 \pm 3.8$ & $\mathrm{NS}$ \\
SRQ-AD-AS & $2.6 \pm 2.0$ & $3.3 \pm 2.1$ & $<0.05$ \\
SRQ-AD-DS & $2.8 \pm 3.0$ & $2.9 \pm 3.1$ & $\mathrm{NS}$ \\
\hline
\end{tabular}

Values are means \pm S.D

NS, Not significant

${ }^{a} P$ value calculated by $t$-tests

5-HTTLPR, Serotonin transporter gene-linked polynorphic region; SRQ-AD-TS; self-rating questionnaire for anxiety and depression total score; SRQ-AD-AS, SRQ-AD-anxiety score; SRQ-AD-DS; SRQ-AD-depression score; 1/1, long/long allele; 1/s, long/short allele; s/s, short/short allele

in anxiety in humans and in animal models, and is the site of action of the widely used serotonin-reuptake-inhibiting antianxiety or antidepressant drugs. Lesch et al. (1996) investigated the association of anxiety-related traits with a polymorphism in the 5HTTLPR, using personality assessment scales, in 505 healthy Caucasians, and reported that individuals with the (s) allele had greater anxiety-related personality characteristics. In the 189 Japanese subjects we tested with the SRQ-AD, the $1 / 1,1 / \mathrm{s}$, and s/s the 5-HTTLPR genotypes were found in 10,55 , and 124 subjects, respectively. Since there were few subjects with the $1 / 1$ genotype, we combined these subjects with those with the 1/s genotype forming (group L) and compared them with subjects with the s/s genotype (group S) for our analysis. There was no significant difference in age distribution between groups $\mathrm{L}$ and $\mathrm{S}$ (Table 1). In group L, the total scores (TS) and depression scores (DS) on the SRQ-AD were lower than those in group $\mathrm{S}$, but there were no significant differences (Table 1). However, there was a significant difference between group L and group $\mathrm{S}$ in the anxiety score (AS). This suggests that populations with the s/s genotype of 5HTTLPR have greater anxiety-related personality traits than those with the 1 allele. This finding was very similar to the results reported by Lesch et al. (1996) in the Caucasian subjects. In our study, however, there was no significant difference between the two groups in the DS on the SRQ$\mathrm{AD}$, suggesting that the polymorphism in 5-HTTLPR was associated with anxiety traits, but not with depressionrelated personality traits, in healthy populations. The dysregulation of 5-HTT function has been reported in various complex behavioral traits and disorders, such as depression, bipolar disorder, obsessive-compulsive disorder, and anxiety (Heils et al. 1996). Ogilvie et al. (1996) found a significant association between major depression and the 9repeat allele of a variable number tandem repeat (VNTR) in intron 2 of this gene in a United Kingdom Caucasian case-control sample. Further studies, including analysis of polymorphisms in the 5-HTT gene in populations with psychiatric disorders, are required to clarify the association of this polymorphism in 5-HTTLPR with anxiety traits. 
Acknowledgments We are grateful to Miss M. Hanada for the preparation of the manuscript.

This work was supported in part by a Grant (8A-8) for Nervous and Mental Disorders from the Ministry of Health and Welfare, Japan, and by a Grant-in-Aid from the Japanese Shipbuilding Industry Foundation, Tokyo, Japan.

\section{References}

Chen HT, Clark M, Goldman D (1992) Quantitative autoradiography of ${ }^{3} \mathrm{H}$-paroxetine binding sites in rat brain. J Pharmacol Toxicol Methods 27: 209-216

El-Rufaie OEF, Absood GH, Abou-Saleh MT (1997) The primary care anxiety and depression (PCAD) scale: A culture-oriented screening scale. Acta Psychiatr Scand 95: 119-124

Heils A, Teufel A, Petri S, Seemann M, Bengle D, Balling U, Riederer P, Lesch KP (1995) Functional promoter and polyadenylation site mapping of the human serotonin (5-HT) transporter gene. J Neural Transm Gen Sect 102: 247-254

Heils A, Teufel A, Petri S, Stober G, Riederer P, Bengel D, Lesch KP (1996) Allelic variation of human serotonin transporter gene expression. J Neurochem 66: 2621-2624

Hensler JG, Ferry RC, Labow DM, Kovachich GB, Frazer A (1994) Quantitative autoradiography of the serotonin transporter to assess the distribution of serotonergic projections from the dorsal raphe nucleus. Synapse 17: 1-15

Lesch KP, Balling U, Gross J, Strauss K, Wolozin BL, Murphy DL, Riederer P (1994) Organization of human serotonin transporter gene. J Neural Transm Gen Sect 95: 157-164

Lesch KP, Bengel D, Heils A, Sabol SZ, Greenberg BD, Petri S, Benjamin J, Muller CR, Hamer DH, Murphy DL (1996) Association of anxiety-related traits with a polymorphism in the serotonin transporter gene regulatory region. Science 274: 1527-1531

Ogilvie AO, Battersby S, Bubb VJ, Fink G, Harmar AJ, Goodwin GM, Smith CAD (1996) Polymorphism in serotonin transporter gene associated with susceptibility to major depression. Lancet 347: 731-733

Tsutsui S (1981) Clinical study on depression in the field of internal medicine (in Japanese). J Med Soc Toho Japan 28: 1-6 